\title{
Load-Unload Response Ratio (LURR), Accelerating Moment/Energy Release (AM/ER) and State Vector Saltation as Precursors to Failure of Rock Specimens
}

\author{
Xiang-Chu Yin ${ }^{1,2}$, Hual-Zhong Yu ${ }^{1}$, Victor Kunshenko ${ }^{3}$, ZhaO-Yong Xu ${ }^{1,5}$, \\ Zhishen Wu ${ }^{1,4}$, Min Li ${ }^{1}$, Keyin Peng ${ }^{1,2}$, Surgey Elizarov ${ }^{6}$, and Qi Li ${ }^{1,4}$
}

\begin{abstract}
In order to verify some precursors such as LURR (Load/Unload Response Ratio) and AER (Accelerating Energy Release) before large earthquakes or macro-fracture in heterogeneous brittle media, four acoustic emission experiments involving large rock specimens under tri-axial stress, have been conducted. The specimens were loaded in two ways: monotonous or cycling. The experimental results confirm that LURR and AER are precursors of macro-fracture in brittle media. A new measure called the state vector has been proposed to describe the damage evolution of loaded rock specimens.
\end{abstract}

Key words: Acoustic emission, LURR, CPH, AM/ER, state vector, precursor of macro-fracture.

\section{Introduction}

The CPH (Critical Point Hypothesis) considers earthquake rupture as a critical point (Vere-Jones, 1977; Sornette and Sornette, 1990; Sornette and Sammis, 1995; Bowman et al., 1998; Rundle et al., 1999; Jaume and SyKes, 1999). According to $\mathrm{CPH}$ the crust is not in a continuous state of criticality, but repeatedly approaches to and retreats from a critical state. During the establishment of criticality the crust must be characterized by both susceptibility to external factors (WEI et al., 2000; XIA et al., 2002) and strong correlation between its different parts. The former will lead to triggering of earthquakes by tidal stress (GRASSO and SORNETTE, 1998) and consequently anomalously high values of

\footnotetext{
${ }^{1}$ LNM (State Key Laboratory of Nonlinear Mechanics), Institute of Mechanics, CAS, Beijing, 100080. E-mail: xcyin@public.bta.net.cn

${ }^{2}$ CAP (Center for Analysis and Prediction), China Seismological Bureau, Beijing 100036.

${ }^{3}$ Ioffe Physical Technique Institute, Russian Academy of Sciences, Petersburg, 194021, Russia. E-mail: Victor. Kuksenko@pop.ioffe.ssi.ru

${ }^{4}$ Ibaraki University, Japan. E-mail: zswu@ipc.ibaraki.ac.jp

${ }^{5}$ Yunnan Province Seismological Bureau, CSB, Kunming 650041. E-mail: xuzhaoyong@netease.com

${ }^{6}$ Interunis Ltd, Prospect Mira, 78, 40, Moscow, Russia. E-mail: serg@interunis.mtu-net.ru
} 
LURR (YIN and YIN, 1991; YIN, 1993; YIN et al., 1994, 1995, 1996, 2000, 2002) are observed prior to large earthquakes. The latter will lead to establishment of long-range correlations in the regional stress field (SYKES and JAUME, 1990; Rundle et al., 1999; SAmmis and Smith, 1999; Mora and Place, 2000, 2002; WEATHERLEY, 2002) and accelerating seismic activity of moderate-sized earthquakes (Ellsworth et al., 1981; Keilis-BoroK, 1990; SornetTe and SAMmi; 1995; KNOPOFF et al., 1996 and BOWMAN et al., 1998) and equivalently, the accelerating seismic release prior to large earthquakes follows a power-law time-to-failure relation - AMR/AER (BUFE and VARNES, 1993; BOWMAN et al., 1998; JAUME and SyKeS, 1999). Various research groups have tested LURR and AMR/AER using seismological observations. In the present work we will test LURR and AMR/AER using acoustic emission (AE) data recorded during rock fracture experiments since there are striking resemblances between acoustic emissions (AE) and earthquakes.

Four tri-axial compression experiments involving rectangular prisms of two kinds of rocks (Wuding gneiss and Wuding sandstone) have been conducted. Wuding gneiss has a Young's modulus of $E=27 \mathrm{GPa}$, Poisson ratio $v=0.26$, density $\rho=2.6 \times 10^{3} \mathrm{~kg} / \mathrm{m}^{3}$ and compressional wavespeed $c=3200 \mathrm{~m} / \mathrm{s}$. Wuding sandstone has a Young's modulus of $E=11 \mathrm{GPa}$, Poisson ratio $v=0.26$, density $\rho=2.2 \times 10^{3} \mathrm{~kg} / \mathrm{m}^{3}$ and compressional wavespeed $c=2150 \mathrm{~m} / \mathrm{s}$. The geometry of the specimens are $105 \times 40 \times 10 \mathrm{~cm}^{3}$ for gneiss and $105 \times 40 \times 15 \mathrm{~cm}^{3}$ for sandstone (see Table 1).

The specimens are loaded in two directions: the axial stress $\sigma_{1}$ and lateral stress $\sigma_{2}$.

Another principal stress $\sigma_{3}$ is zero so that:

$$
\sigma_{1} \neq \sigma_{2} \neq \sigma_{3}
$$

In other words, the stress state is a tri-axial stress state (Fig. 1). Under such a stress state all of the specimens undergo shear failure.

The loading history in our experiments has two types: monotonous loading (Fig. 3, top chart) and cycling loading (Fig. 2, top chart).

Table 1

Parameters of tested specimens

\begin{tabular}{cccccc}
\hline Type & Sample & Geometry $\left(\mathrm{cm}^{3}\right)$ & Lateral & Axial & $\mathrm{Z}$ \\
\hline Gneiss & G1 & $105 \times 40 \times 10$ & $5.6 \mathrm{MPa}$ & Monotonously & 0.46 \\
Gneiss & G2 & $105 \times 40 \times 10$ & $5.6 \mathrm{MPa}$ & Cycle loading & 0.45 \\
Sandstone & S1 & $105 \times 40 \times 15$ & $3.73 \mathrm{MPa}$ & Monotonously & 0.29 \\
Sandstone & S2 & $105 \times 40 \times 15$ & $3.73 \mathrm{MPa}$ & Cycle loading & 0.42 \\
\hline
\end{tabular}




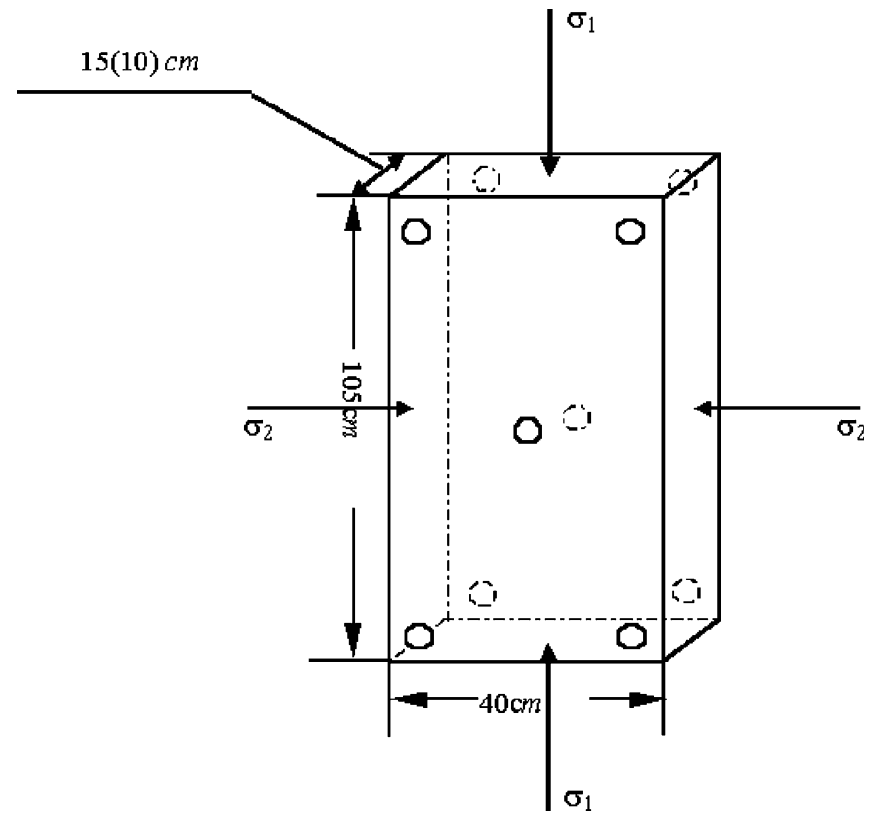

Figure 1

The geometry of the specimens, the loading conditions, and the arrangement of AE sensors (circles).

\section{Experiment and its Results}

The AE signals are recorded continuously with an A-line 32D - AE system made by A.F Ioffe Physical Technical Institute, Russian Academy of Sciences and Interunis Ltd. The A-line 32D - AE system is a 32 channel AE system. Each channel consists of an AE sensor, a preamplifier and an AECB (Acoustic Emission Channel Board).

The AE sensors pick up the sound waves from the specimens and convert them into an electrical signal that is then amplified by a preamplifier and converted into a digital data stream in an AECB. AE features such as arrival times, rise-times, duration, peak amplitude, energy and counts are extracted by a FPGA (Field Programmable Gate Array). The input filter has frequency range from $10 \mathrm{kHz}$ to $500 \mathrm{kHz}[-3 \mathrm{~dB}]$ and $24 \mathrm{~dB} /$ octave. The ADC is operated at a $5 \mathrm{MHz}$ sampling frequency and provides the 16 bit resolution. The threshold values are from 45 to $51 \mathrm{~dB}$ and its resolution is $1 \mu \mathrm{V}$. The working frequency of the sensor ranges $100-500 \mathrm{kHz}$ and its sensitive factor on $175 \mathrm{kHz}$ is $67 \mathrm{~dB}$ relative to $1 \mathrm{~B} / \mathrm{m} / \mathrm{sec}$. In parallel to the feature extraction, the complete waveform can also be recorded. $\mathrm{AE}$ events are located in real time and can be displayed on a screen and recorded for post-processing.

The experimental results for cycling loading are shown in Figure 2 and the results for monotonous loading are shown in Figure 3. 
(a)

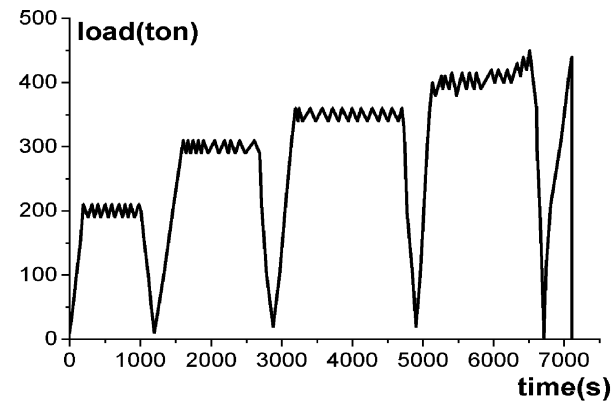

(b) 1200 events $/$ s $^{-1}$ (s)
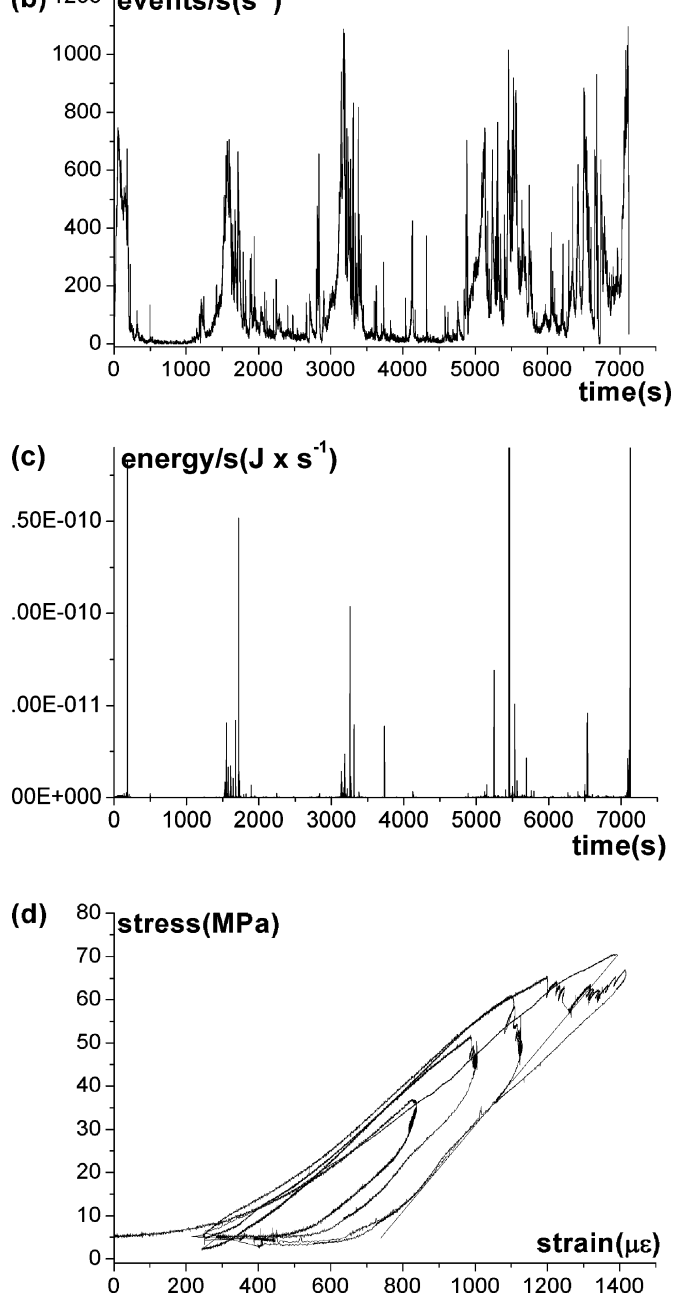

Figure 2

The cycling stress history (a) for specimen S2 (sandstone), the corresponding experimental results - AE event rate (b) and AE energy rate (c) and the stress-strain curve (d). 


\section{3. $L U R R$}

GRASSO and SORNETTE (1998) have proposed an approach to test for criticality, which is to monitor the response of the crust to perturbations leading to induce seismicity. YIN and YIN (1991), YIN (1993), YIN et al (1994, 1995, 2000, 2002) has proposed another approach, to test for crustal criticality, called the Load-Unload Response Ratio (LURR) which is defined as

$$
Y=\frac{X^{+}}{X^{-}}
$$

where $X^{+}$and $X^{-}$are the response rates during loading and unloading according to some measures.

The idea that motivated the LURR earthquake prediction approach is that when a system is stable, its response to loading is nearly the same as its response to unloading so LURR $\sim 1$, whereas the response to loading and unloading becomes quite different and LURR $>1$ when the system is approaching a critical state.

High LURR values indicate that a region is prepared for a strong earthquake. In previous years, a series of successful intermediate-term predictions have been made for strong earthquakes in China and other countries using the LURR parameter (YIN and YIN, 1991; YIN, 1993; YIN et al., 1994, 1995, 1996, 2000, 2002). Usually the released seismic energy is adopted as the "response" after which the LURR is defined as:

$$
Y_{m}=\frac{\left(\sum_{i=1}^{N^{+}} E_{i}^{m}\right)_{+}}{\left(\sum_{i=1}^{N^{-}} E_{i}^{m}\right)_{-}}
$$

where $E$ denotes released seismic energy, the sign "+ " means loading and "-" means unloading, $m=0$ or $1 / 3$ or $1 / 2$ or $2 / 3$ or 1 .

For $m=1, E^{m}$ is exactly the energy itself; for $m=1 / 2, E^{m}$ denotes the Benioff strain; for $m=1 / 3,2 / 3, E^{m}$ represents the linear scale and area scale of the focal zone respectively; and for $m=0, Y$ is equal to $N+/ N-$, where $N+$ and $N$ - denote the number of earthquakes occurring during the loading and unloading periods, respectively.

Typically the $Y$ - $t$ curve is like that of Figure 4. While the LURR reaches to a high value several months or years prior to the occurrence of strong earthquakes, in the eve of large earthquakes the LURR decreases to a low level and then the large event occurs.

The results of LURR in this experiment are shown in Figure 5 for sample G2 and S2. Prior to the final failure of the specimens, the LURR reaches to a high value, and then the LURR decreases prior to the occurrence of macro-fracture. The experimental results coincide with the seismological observations very well, suggesting that both macro-fracture of rock specimens and earthquakes are examples of CP (Critical Point) behavior. 
(a) ${ }^{450}$ load(ton)
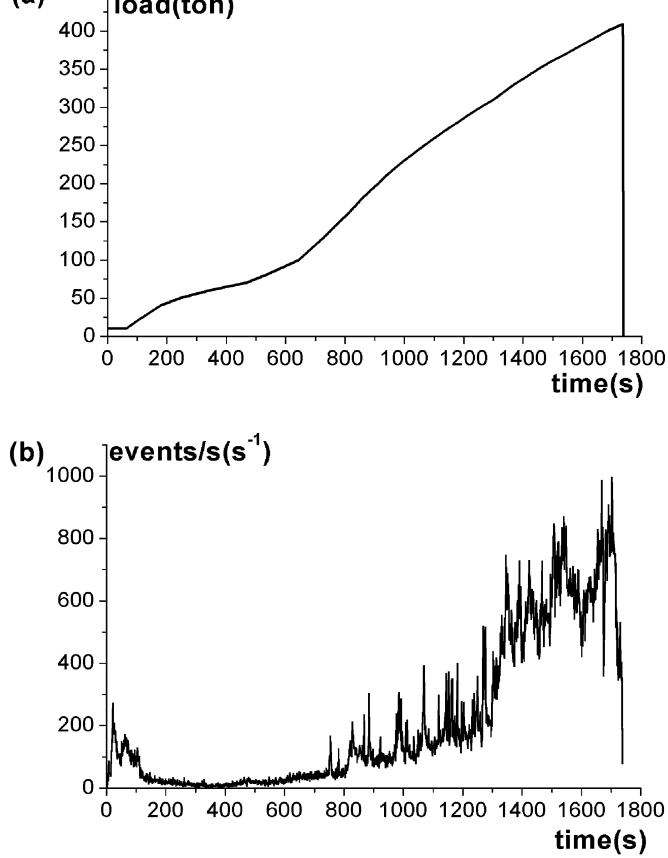

(c)

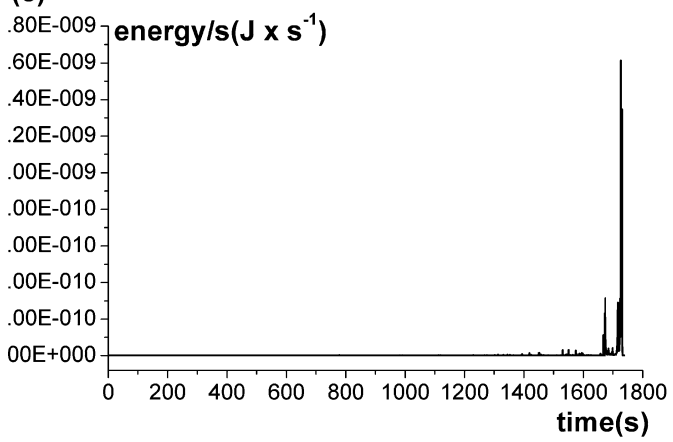

(d) 70 stress(MPa)

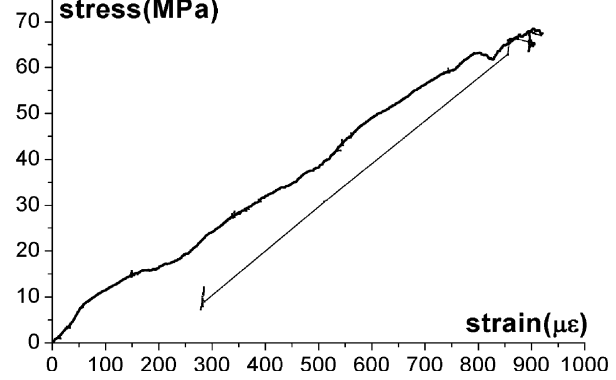




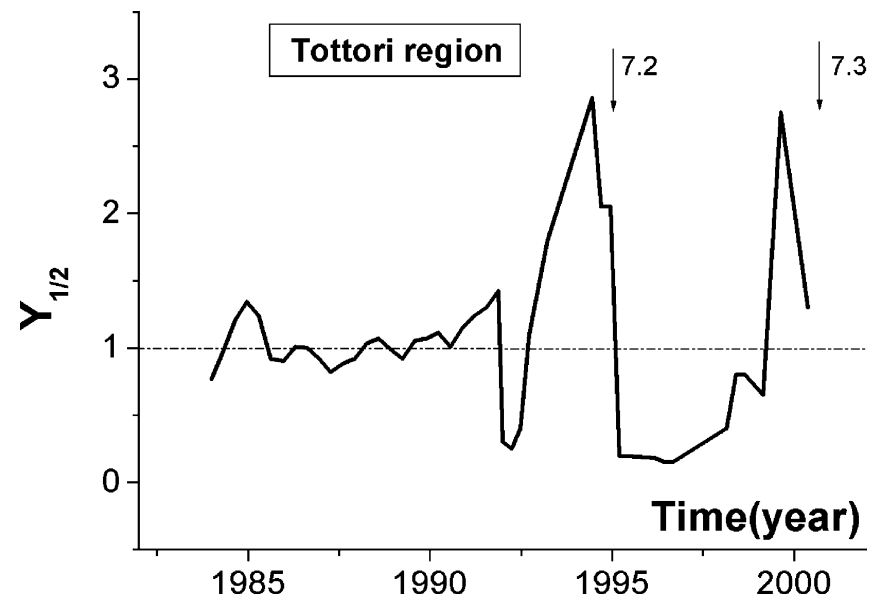

Figure 4

The LURR anomaly prior to the Kobe and Tottori earthquakes.

(a)

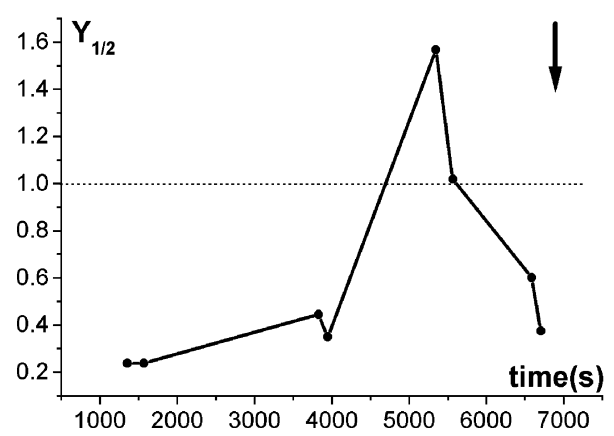

(b)

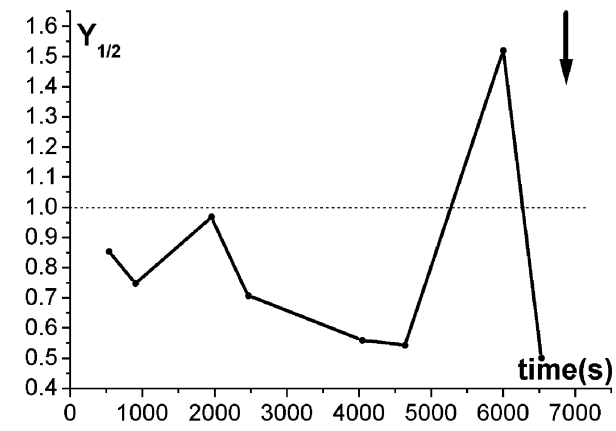

Figure 5

The LURR anomaly during rock fracture experiments involving (a) specimen G2 and (b) specimen S2.

\section{AER (Accelerating Energy Release)}

Prior to the occurrence of large or great earthquakes the seismic energy release accelerates. In many cases this acceleration can be modeled using a power-law time-to-failure relation. The function has the following form:

$$
\sum_{t=0}^{t_{c}} \sqrt{E}=A+B\left(t_{c}-t\right)^{z}
$$


where $E$ is the seismic energy release, $t_{c}$ is the time of large earthquake, $t$ is the time of the last measurement of $E$ and $A, B$ and $z$ are empirical constants.

Figures 6 (a, b, c, d) show the experimental results for specimens G1, G2, S1 and $\mathrm{S} 2$ and the best fit to Equation (3) for each specimen. The results confirm that energy release accelerates prior to macro-failure of the specimens, in agreement with the $\mathrm{CPH}$ once again.

In this context, the exponent $z$ is a focus of the problem. SornetTe (1992) found that $z=1 / 2$ is associated with a critical transition. RUNDLE et al. (2000) used scaling arguments to demonstrate that power-law time-to-failure buildup of cumulative Benioff strain may represent the scaling regime of a spinodal phase transition, with an exponent $z=1 / 4$. BEN-ZION and LYAKHOVSKY (2002) concluded that $z=1 / 3$ for the damage rheology model of LyAKHOvsky et al. (1997), and TurCotTe et al. (2002) obtained similar results using a fiber-bundle model. BEN-ZION and LYAKHOVSKY (2002) have listed the $z$ value of seismological observations from various authors. The exponents fall in the range 0.1 to 0.55 with the peak of the distribution at $z=0.29$. Our experimentally measured $z$-values are $0.46,0.45,0.29$, and 0.42 for specimens G1, G2, S1 and S2, respectively. Our results are in general agreement with the results mentioned above. The scatter in $z$-values of our experiments is similar to

(a)

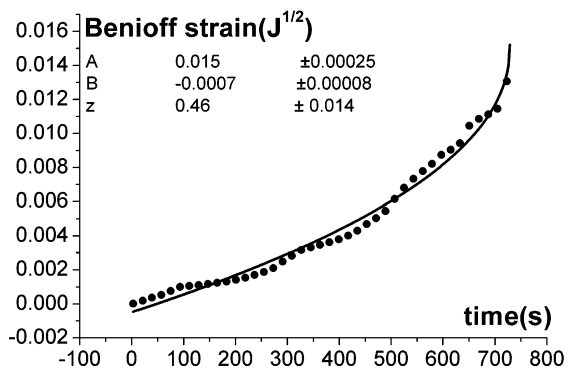

(c)

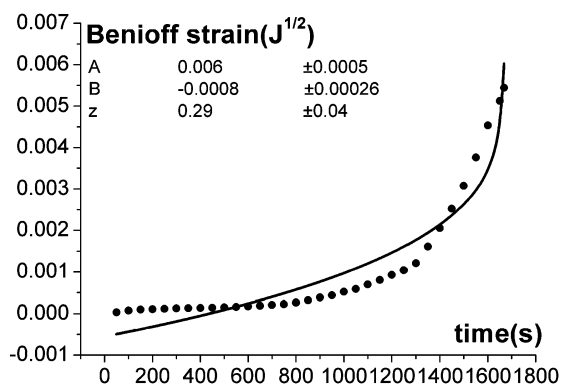

(b)

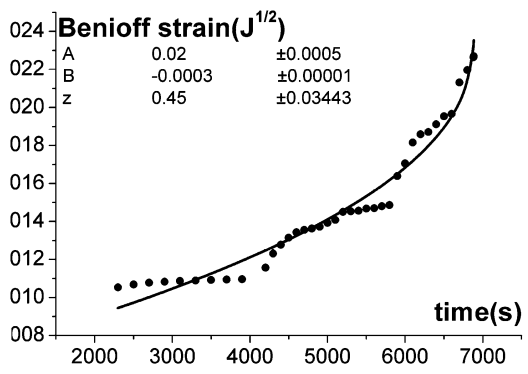

(d)

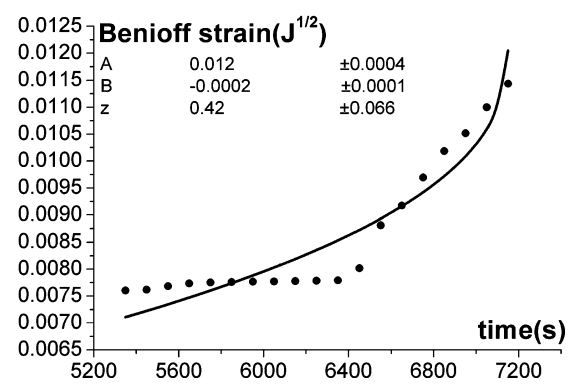

Figure 6

The AER curves prior to rock fracture for (a) monotonous loading of specimen G1, (b) cycling loading of specimen G2, (c) monotonous loading of specimen S1, and (d) cycling loading of specimen S2. 
that seen in observational earthquake data AER studies (BEN-ZION and LYAKHOVSKY, 2002). The $z$ values of gneiss specimens are larger obviously than those of sandstone specimens since the mechanical properties of gneiss are more heterogeneous than sandstone, which suggests that the $z$ value for the crust with complex structures could be larger than that for the region with homogeneous crust.

\section{State Vector}

The state vector is an idea stemming from statistical physics (REICHL, 1980). Here it is used to describe the evolution of damage in rock specimens. The whole specimen can be divided into $n$ regions (Fig. 7). A specified physical parameter representing the micro-damage of the specimen (e.g., AE energy or AE event rate, etc.) in region $i$ at time $t_{k}$ denotes the $i$-th component of an n-dimension vector $V_{k}$ which is called the state vector.

The state vector $V_{k}$ at time $t_{k}$ is a point in the n-dimension phase space. Different state vectors $V_{k}$ at different times form a trajectory in the phase space (Fig. 8). The trajectory could be a tool to describe the damage evolution during experiments. For example, the modulus of the state vector indicates the global state of the damage evolution of the whole specimen and the included angle $\varphi_{i j}$ between $V_{i}\left(\mathrm{t}=\mathrm{t}_{i}\right)$ and $V_{j}$ $\left(\mathrm{t}=\mathrm{t}_{j}\right)$ mirrors the change in the damage pattern of the specimen from $\mathrm{t}_{i}$ to $\mathrm{t}_{j}$.

For the experiment involving specimen G1, the state vector is computed using the AE Benioff strain recorded within each of $n=24$ subdivisions of the specimen. Figure 9 is a plot of the included angle $\varphi_{i j}(t)$ and modulus $M(t)$ of the state vector.

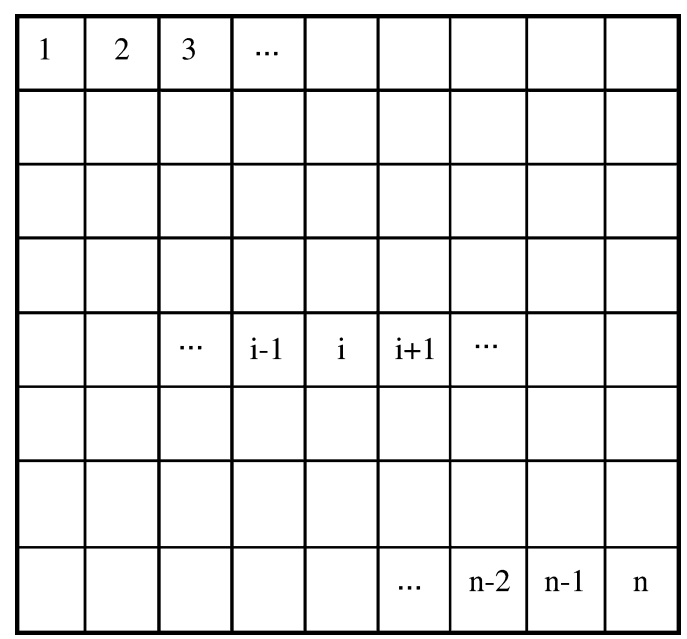

Figure 7

Subdivision of a specimen into $n$ parts. 


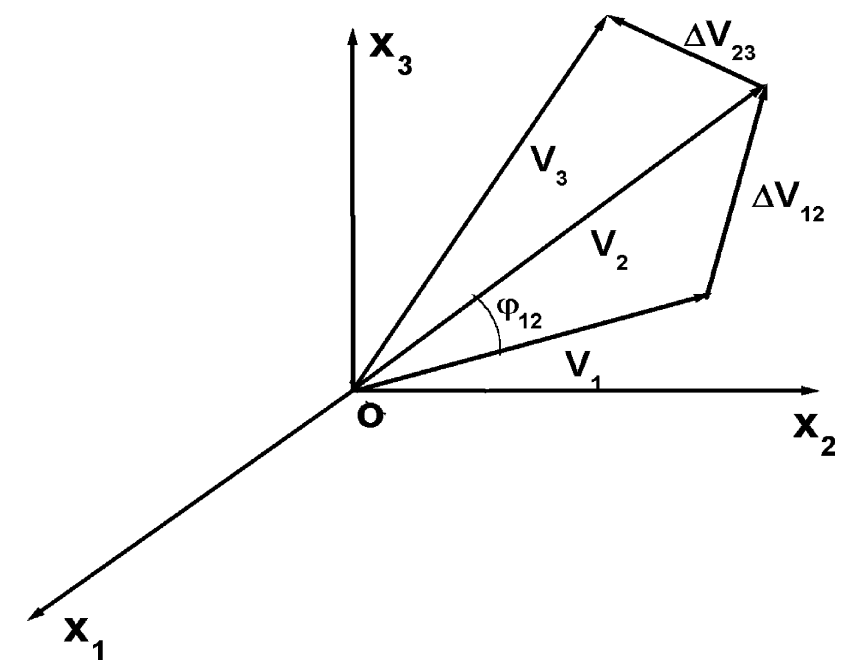

Figure 8

State vector in $3-\mathrm{D}$ phase.
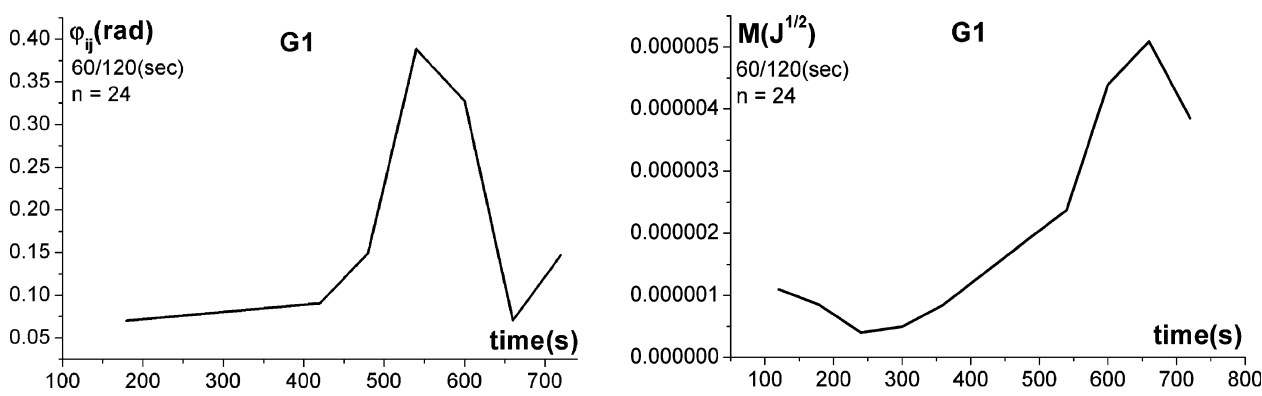

Figure 9

The change in phase angle $\varphi_{i j}(t)$ and modulus $M(t)$ of the state vector for specimen G1 (gneiss).

During the first stage of the experiment, there is no coalescence of microcracks within the specimen so $\varphi_{i j}(t)$ and $M(t)$ simply fluctuate at a low level. When the microcracks begin to coalesce into larger fractures the damage state of the various subregions changes severely as evidenced by sharp peaks in both curves. Subsequent to the peak damage evolution, the final fracture occurs.

\section{Summary}

AE recorded during four tri-axial compression experiments involving two types of rock specimens confirms that anomalously high LURR values and AER precede macro-fracture of the specimens. These results are interpreted as evidence that brittle 
failure of heterogeneous media is a $\mathrm{CP}$ phenomenon. A novel measure to describe damage evolution of fracturing specimens, known as the state vector, is also introduced. Using AE data recorded during one of the compression experiments, it is demonstrated that the modulus and change in the phase angle of the state vector show sharp peaks during the period in which micro-cracks coalesce into larger fractures, prior to the final failure of the specimen. The state vector may have application in describing the damage evolution or the seismogenic process for a specified region of the Earth's crust.

\section{Acknowledgements}

This research is supported by Natural Sciences Foundation of China (Grant No. 10232050 and 40004002), China Special Funds for Major State Basic Research Project under Grant No. 2002 CB412706 and Supercomputing Center of Computer Network Information Center, Chinese Academy of Sciences (INF105-SCE-2-02).

\section{REFERENCES}

Ben-Zion, Y. and Lyakhovsky, V. (2002), Accelerated Seismic Release and Related Aspects of Seismicity Patterns on Earthquake Faults, Pure Appl. Geophys. 159, 2385-2412.

Bowman, D. D., Oulllon, G., Sammis, C. G., Sornette, A., and Sornette, D. (1998), An Observational Test of the Critical Earthquake Concept, J. Geophys. Res. 103, 24359-24372.

Bufe, C. G. and Varnes, D. J. (1993), Predictive Modeling of the Seismic Cycle of the Greater San Francisco Bay Region, J. Geophys. Res. 98, (B6), 9871-9883.

Ellsworth, W. L., Lindh, A. G., Prescott, W. H., and Head, D. G., The 1906 San Francisco earthquake and the seismic cycle. In Earthquake Prediction: An International Review (eds. Simpson, D. W., and Richards, P. G.) (AGU, Washington, D. C. 1981) pp. 21-27.

Grasso, J. and Sornette, D. (1998), Testing Self-organized Criticality by Induced Seismicity, J. Geophys. Res. 103, (B12), 29,965-29,987.

Jaume, S. C. and Sykes, L. R. (1999), Evolving towards a Critical Point: A Review of Accelerating Seismic Moment/Energy Release prior to Large and Great Earthquakes, Pure Appl. Geophys. 155, $279-306$.

KeILIS-Borok, V., The Lithosphere of the Earth as a large nonlinear system. In Quo Vadimus: Geophysics for the Next Generation, Geophys. Monogr. Ser. (eds. G. D. Garland and J. R. Apel) (AGU, Washington, D. C. 1990) 60, pp. 81-84.

Knopoff, L., Levshina, T., Keilis-Borok, V. I., and Mattoni, C. (1996), Increased Long-range Intermediate-magnitude Earthquake Activity prior to Strong Earthquakes in California, J. Geophys. Res. 101, 5779-5796.

Lyakhovsky, V., Ben-Zion, Y., and Agnon, A. (1997), Distributed Damage. Faulting and Friction, J. Geophys. Res. 102, 27,635-27,649.

Lyakhovsky, V., Ben-Zion, Y., and Agnon, A. (2001), Earthquake Cycle, Fault Zones, and Seismicity Patterns in a Rheologically Layered Lithosphere, J. Geophys. Res. 106, 4103-4120.

Mora, P., Place, D., Abe, S., and Jaume, S., Lattice solid simulation of the physics of fault zones and earthquakes: The model, results and directions. In Geocomplexity and the Physics of Earthquakes (eds. Rundle, J. B., Turcotte, D. L., and Klein, W.) (AGU, Washington, DC 2000) pp. 105-125.

Mora, P. and Place, D. (2002), Stress Correlation Function Evolution in Lattice Solid Elasto-dynamic Models of Shear and Fracture Zones and Earthquake Prediction, Pure Appl. Geophys. 159, 2413-2428. 
ReIChl, L. E., A Modern Course in Statistical Physics (University of Texas 1980).

Rundle, J. B., Klein, W., and Gross, S. (1999), A Physical Basis for Statistical Patterns in Complex Earthquake Populations: Models, Predictions and Tests, Pure Appl. Geophys. 155, 575-607.

Rundle, J. B., Klein, W., Tiampo, K., and Gross, S. (2000), Precursory Seismic Activation and Criticalpoint Phenomena, Pure and Appl. Geophs. 157, 2165-2182.

Sammis. C. G. and Smith, S. W. (1999) Seismic Cycles and the Evolution of Stress Correlation in Cellular Automation Models of Finite Fault Networks, Pure Appl. Geophys. 155, 307-334.

Sornette, A. and Sornette, D. (1990), Earthquake Rupture as a Critical Point: Consequences for Telluric Precursors, Tectonophysics 179, 327-334.

Sornette, D. (1992), Mean-field Solution of a Block-spring Model of Earthquake, J. Phys. I France 2, 2089-2096.

Sornette, D. and Sammis, C. G. (1995), Complex Critical Exponents from Renormalization Group Theory of Earthquake Prediction, J. Phys. I. France. 5, 607-619.

Sykes, L. R. and Jaume, S. (1990), Seismic Activity on Neighboring Faults as a Long-term Precursor to Large Earthquakes in the San Francisco Bay Area, Nature 348, 595-599.

Turcotte, D. L., Newman, W. I., and Shcherbakov, R. (2002), Micro- and Macroscopic Models of Rock Fracture, Geophys. J. Int. 152, 718-728.

Vere-Jones, D. (1977), Statistical Theory of Crack Propagation, Math Geol. 9, 455-481.

Weatherley, D., Mora, P., and XIA, M. (2002), Long-range Automaton Models of Earthquakes: Power-law Accelerations, Correlation Evolution, and Mode Switching, Pure Appl. Geophys, 159, 24692490.

WeI, Y. J., XIA, M. F., Ke, F. J., YIN, X. C., and BAI, Y. L. (2000), Evolution-induced Catastrophe and its Predictability, Pure Appl. Geophys. 157, 1945-1957.

XiA, M. F., WeI, Y. J, Ke, F. J., and BAI, Y. L. (2002), Critical Sensitivity and Transscale Fluctuations in Catastrophic Rupture, Pure Appl. Geophys. 159, 2491-2510.

Yin, X. C. and YIn, C. (1991), The Precursor of Instability for Nonlinear Systems and its Application to Earthquake Prediction, Science in China 34, 977-986.

YIN, X. C. (1993), New Approach to Earthquake Prediction, Preroda (Russia's "Nature"). 1, 21-27 (in Russian).

Yin, X. C., CAN YIn and Xue-Zhong Chen., The Precursor of Instability for Nonlinear System and Its Application to Earthquake Prediction-the load-Unload Response Ratio Theory ", Nonlinear Dynamics and Predictability of Geophysical Phenomena” (eds. Neuman ,W.I , Gabrelov, A. M., and Turcotte, D.L.) (AGU Geophysical Monograph 83. 1994) pp. 55-60,

Yin, X. C., Chen, X. Z., Song, Z. P., and Yin, C. (1995), A New Approach to Earthquake Prediction-the Load-Unload Response Ratio (LURR) Theory, Pure Appl. Geophys. 145, (3/4), 701-715.

Yin, X. C., Chen, X. Z., Song, Z. P., and Wang, Y. C. (1996), The Temporal Variation of LURR in Kanto and Other Regions in Japan and its Application to Earthquake Prediction, Earthquake Research in China 10, 381-385.

Yin, X. C., Wang, Y. C., Peng, K. Y., Bai, Y. L., Wang, H., and Yin, X. F. (2000), Development of a New Approach to Earthquake Prediction: Load/Unload Response Ratio (LURR) Theory, Pure Appl. Geophys. 157, 1923-1941.

Yin, X. C., Mora, P., Peng, K. Y., Wang, Y. C., and Weatherly, D. (2002), Load-Unload Response Ratio and Accelerating Moment/Energy Release, Critical Region Scaling and Earthquake Prediction, Pure Appl. Geophys. 159, 2511-2524.

(Received September 27, 2002, revised February 28, 2003, accepted March 7, 2003)

To access this journal online:
http://www.birkhauser.ch 